\title{
Desenvolvimento inicial e estado nutricional de clones de eucalipto no nordeste do Pará'
}

\author{
Gilson Sergio Bastos de MATOS², George Rodrigues da SILVA33, Marcos André Piedade GAMÁ, \\ Rodrigo Silva do VALE 5 , Jonas Elias Castro da ROCHA ${ }^{6}$
}

\begin{abstract}
RESUMO
O objetivo desta pesquisa foi avaliar o desenvolvimento inicial, nutrição e fertilidade do solo em plantio de clones de eucalipto no nordeste do Pará. Os tratamentos constaram de cinco clones (Eucalyptus grandis x E. urophylla - 03 e 09, E. urophylla x E. camaldulensis - 32, E. grandis $\mathrm{x}$ E. pellita -07 e E. camaldulensis - 11), dispostos em delineamento de blocos ao acaso com quatro repetiçôes. Cinco meses após plantio foram avaliadas a altura e sobrevivência das plantas. Aos 18 meses, além dessas variáveis, foram avaliados o diâmetro à altura do peito (DAP), a fertilidade do solo (profundidades 0-10 e 10-20 cm) e os nutrientes foliares. A altura e o DAP das árvores não variaram entre clones nas épocas de avaliação. Houve diferença na porcentagem de sobrevivência apenas aos 18 meses, sendo do clone 07 a menor média apresentada. Na camada de $0-10 \mathrm{~cm}$ foram observados os menores valores de $\mathrm{K}$ trocável no solo sob os clones 09 e 07 , nas parcelas deste último foram observado também a menor CTC. Na camada de 10-20 cm, o menor valor de $\mathrm{N}$ no solo esteve sob o clone 32, enquanto que o K e Ca trocáveis foram encontrados em maiores quantidades sob o clone 03 . De maneira geral, foram observadas as maiores concentraçóes de todos os nutrientes, com exceção do N, nas folhas dos clones 11 e 32. Desta forma, os clones apresentaram respostas nutricionais diferentes na área de estudo, assim como o solo sob cada material genético apresentou valores variados de fertilidade. Essas variaçóes, entretanto, pouco foram observadas no desenvolvimento inicial das árvores.
\end{abstract}

PALAVRAS-CHAVE: reflorestamento; fertilidade do solo; Eucalyptus grandis x E. urophylla; E. pellita; E. camaldulensis.

\section{Initial growth and nutritional status of Eucalyptus clones in northeast of Para State}

\section{ABSTRACT}

The objective of this research was to determine the initial growth, nutrition and soil fertility of Eucalyptus plantation in Moju, northeast city of Para State, Brazil. The treatments used were five clones (Eucalyptus grandis x E. urophylla - 03 e 09, E. urophylla $\mathrm{x}$ E. camaldulensis - 32, E. grandis $\mathrm{x}$ E. pellita -07 e E. camaldulensis - 11), organized in a randomized blocks design with four replications. Five months after planting, the height and survival percentage of plants were measured. At 18 months, besides these variables, diameter, soil fertility at the 0-10 and 10-20 cm depth and plant mineral nutrition were evaluated. The height and diameter did not vary among clones at evaluated times. There was difference in survival percentage just at 18 months, when the 07 clone showed the lower average. At the $0-10 \mathrm{~cm}$ soil depth, the lowest $\mathrm{K}$ exchangeable was observed under the 09 and 07 clones, the clone 07 also presented the lowest soil CEC. In 10-20 cm depth, the lowest value of $\mathrm{N}$ was observed in 32 clone, while the $\mathrm{K}$ and $\mathrm{Ca}$ were observed in highest levels in 03 clone. In general, higher macro and micronutrients leaves contents were found in the 11 and 32 clones, exception $\mathrm{N}$. The clones presented different nutritional responses over the researched area, as well as the soil fertility under each clone presented varied values. Such variations, however, were little observed in the tree initial growth.

KEYWORDS: reforestation; soil fertility; Eucalyptus grandis x E. urophylla; E. pellita; E. camaldulensis.

\footnotetext{
1 Parte da Dissertação de Mestrado do Primeiro Autor no Programa de Pós-Graduação em Agronomia da Universidade Federal Rural da Amazônia

2 Universidade Federal Rural da Amazônia, Avenida Presidente Tancredo Neves, № 2501, Bairro Montese, Cep 66.077-901, Belém-Pará: gilsonsbm@yahoo.com.br

3 Universidade Federal Rural da Amazônia, Avenida Presidente Tancredo Neves, № 2501, Bairro Montese, Cep 66.077-901, Belém-Pará: george.silva@ufra.edu.br

${ }^{4}$ Universidade Federal Rural da Amazônia, Avenida Presidente Tancredo Neves, № 2501, Bairro Montese, Cep 66.077-901, Belém-Pará: marcos.gama@ufra.edu.br

${ }^{5}$ Universidade Federal Rural da Amazônia, Avenida Presidente Tancredo Neves, № 2501, Bairro Montese, Cep 66.077-901, Belém-Pará: rodrigo.vale@ufra.edu.br

${ }_{6}^{6}$ Vale Florestar S. A., Rodovia BR - 010, Km 16, s/n, Zona Rural, Cep 68.633-000, Dom Eliseu-Pará: jonas.castro@valeflorestar.com
} 


\section{INTRODUÇÃO}

Os plantios de eucalipto alcançaram 4,5 milhóes de hectares no Brasil, área representativa de $66 \%$ do total de florestas plantadas do país (ABRAF 2010). O sucesso das florestas de eucalipto é decorrente da grande quantidade de pesquisas realizadas pelo setor florestal, tanto no nível acadêmico como no empresarial. Os atrativos econômicos provenientes da eucaliptocultura têm levado essa atividade a regióes menos tradicionais quanto ao plantio dessas espécies, como é o caso da Amazônia. Para os Estados componentes dessa regiâo, o plantio de espécies florestais de rápido crescimento em áreas já alteradas pode amenizar a pressão sobre as florestas nativas (Silva et al. 2004; Souza et al. 2004).

$\mathrm{Na}$ Amazônia oriental, notadamente no nordeste e sudeste do Estado do Pará e oeste do Estado do Maranhão, tem ocorrido crescimento da demanda por carvão vegetal visando atender os fornos de beneficiamento de minérios, principalmente ferro gusa. Segundo Santos (2010), o Brasil é o maior produtor mundial de ferro gusa a carvão vegetal, sendo o Estado do Pará no ano de 2007, o segundo maior produtor desse minério, representando $36 \%$ da produçáo nacional, atrás apenas do Estado de Minas Gerais, com 56,6\% da produção brasileira. As empresas da região Amazônica dispóem de poucos estudos a respeito de espécies de eucalipto, principalmente as destinadas para fins energéticos, e as informaçôes existentes dificilmente são divulgadas. Assim, as pesquisas de materiais genéticos com potencial para carváo são essenciais para o sucesso da atividade na regiáo.

Avaliaçóes de campo testando o desenvolvimento de espécies, procedências ou clones de eucaliptos, bem como monitoramentos nutricionais dos plantios, são essenciais para auxiliar produtores na escolha de materiais genéticos superiores em produtividade (Caldeira et al. 2002; Faria et al. 2008; Vilas Bôas et al. 2009).

Em relação ao manejo nutricional, nos plantios florestais a análise química foliar e do solo são as ferramentas mais utilizadas na recomendação de adubação e no diagnóstico de deficiência de nutrientes (Macedo et al. 1996; Magalhães e Blum 1999). A análise das folhas é confiável porque é neste órgão que ocorre maioria das atividades metabólicas e seu status nutricional e fisiológico pode influenciar o crescimento das plantas (Wadt 2004).

Trabalhos científicos têm demonstrado que indivíduos de mesma espécie apresentam desenvolvimento e estado nutricional distintos quando avaliados em regiôes ecológicas diferentes, assim como espécies diferentes de eucaliptos podem reproduzir respostas bem variadas em um mesmo sítio florestal (Drumond et al. 1998; Drumond et al. 2003; Coutinho et al. 2004). Essas variaçôes são conseqüências das distinçôes climáticas e de solo das diversas regiôes brasileiras e da heterogeneidade dos materiais genéticos (Santana et al. 1999; Santana et al. 2002).

Queiroz et al. (2009), trabalhando com plantio de sete materiais genéticos de eucalipto aos 18 meses de plantados no Rio de Janeiro, observaram que Eucalyptus urophylla, E. grandis e o híbrido E. urophylla $\mathrm{x}$ E. grandis destacaram-se quanto ao crescimento e estabelecimento no campo em detrimento de E. camaldulensis, E. saligna, E. pellita e Corymbia citriodora. Segundo esses autores as maiores concentraçóes foliares de macronutrientes foram encontradas para E. grandis. Para Wadt et al. (1999) diferenças nutricionais entre espécies sobre as mesmas condiçóes climáticas e de fertilidade do solo são atribuídas às particularidades nutricionais de cada material genético, que podem estar relacionadas à diferentes eficiência de utilização e capacidades de absorção de nutrientes.

Desta forma, o objetivo deste trabalho foi avaliar o desenvolvimento inicial, a fertilidade do solo e o estado nutricional, bem como a correlação entre esses parâmetros, aos cinco e 18 meses de plantio com cinco clones de Eucalyptus, no município de Moju, nordeste Paraense.

\section{MATERIAL E MÉTODOS}

A pesquisa foi realizada em uma área de plantio comercial de eucalipto localizada no município de Moju, nordeste do Pará, a 90 km da capital Belém, iniciada em março de 2009, cinco meses após o plantio no campo, e foi desenvolvida até outubro de 2010. A área de plantio está situada nas coordenadas 1' 49' 43" de latitude Sul W 48 44' 96" de longitude Oeste do meridiano de Greenwich. A região, segundo a classificação de Köppen, possui clima do tipo Ami com temperatura média anual variando de 25 a $27^{\circ} \mathrm{C}$. A precipitação pluviométrica anual varia de 2000 a $3000 \mathrm{~mm}$ com as chuvas distribuídas irregularmente, mas com um período seco definido de agosto a outubro (Nemer e Jardim 2004). Ainda, segundo Sousa (2006), com base em dados de balanço hídrico dos anos de 1989 a 2005 do município de Moju, no mês de agosto a novembro é registrado um período onde o estoque de água no solo é rapidamente esgotado, caracterizado por deficiência hídrica, o que pode interferir no desenvolvimento da planta, principalmente na absorção de nutrientes.

O solo da área experimental, de acordo com Embrapa (2006), é classificado como Latossolo Amarelo distrófico textura média, relevo plano. A caracterização dos atributos químicos, assim como a granulometria foi determinada a partir três amostras compostas (três profundidades) de 25 amostras simples cada, retiradas a partir de um caminhamento aleatório abrangendo toda a área 30 dias antes da instalação do plantio (Tabela 1). 
Tabela 1 - Atributos de Latossolo Amarelo distrófico textura média, um mês antes da instalação do experimento com clones de eucalipto, no município de Moju, Pará.

\begin{tabular}{|c|c|c|c|c|}
\hline \multirow{2}{*}{ Atributos $^{1}$} & & \multicolumn{3}{|c|}{ Profundidade (cm) } \\
\hline & & $0-10$ & $10-20$ & $20-40$ \\
\hline $\mathrm{pH}$ & $\mathrm{H}_{2} \mathrm{O}$ & 4,25 & 4,17 & 4,32 \\
\hline M.0 & $\mathrm{g} \mathrm{kg}^{-1}$ & 17,90 & 16,11 & 8,94 \\
\hline $\mathrm{N}$ & $\mathrm{g} \mathrm{kg}^{-1}$ & 1,67 & 1,10 & 0,96 \\
\hline$P$ & $\mathrm{mg} \mathrm{dm}^{-3}$ & 1,76 & 1,96 & 0,97 \\
\hline K & $\mathrm{cmol}_{\mathrm{c}} \mathrm{dm}^{-3}$ & 0,09 & 0,08 & 0,00 \\
\hline $\mathrm{Ca}$ & $\mathrm{cmol}_{\mathrm{c}} \mathrm{dm}^{-3}$ & 0,36 & 0,44 & 0,22 \\
\hline$M g$ & $\mathrm{cmol}_{\mathrm{c}} \mathrm{dm}^{-3}$ & 0,36 & 0,27 & 0,13 \\
\hline $\mathrm{Al}$ & $\mathrm{cmol}_{\mathrm{c}} \mathrm{dm}^{-3}$ & 0,97 & 0,97 & 0,97 \\
\hline $\mathrm{H}+\mathrm{Al}$ & $\mathrm{cmol}_{\mathrm{c}} \mathrm{dm}^{-3}$ & 4,64 & 4,86 & 2,59 \\
\hline SB & $\mathrm{cmol}_{\mathrm{c}} \mathrm{dm}^{-3}$ & 0,8 & 0,8 & 0,4 \\
\hline CTC (pH 7,0) & $\mathrm{cmol}_{\mathrm{c}} \mathrm{dm}^{-3}$ & 5,4 & 5,7 & 2,9 \\
\hline V & $\%$ & 14,7 & 14,0 & 12,1 \\
\hline $\mathrm{m}$ & $\%$ & 54,9 & 55,1 & 73,1 \\
\hline $\mathrm{Cu}$ & $\mathrm{mg} \mathrm{dm}^{-3}$ & 0,17 & 0,24 & 0,34 \\
\hline $\mathrm{Fe}$ & $\mathrm{mg} \mathrm{dm}^{-3}$ & 68,08 & 69,23 & 83,14 \\
\hline $\mathrm{Mn}$ & $\mathrm{mg} \mathrm{dm^{-3 }}$ & 0,43 & 0,20 & 0,24 \\
\hline $\mathrm{Zn}$ & $\mathrm{mg} \mathrm{dm}^{-3}$ & 0,11 & 0,12 & 0,13 \\
\hline Areia & $\mathrm{g} \mathrm{kg}^{-1}$ & 680 & 630 & 600 \\
\hline Silte & $\mathrm{g} \mathrm{kg}^{-1}$ & 80 & 80 & 60 \\
\hline Argila & $\mathrm{g} \mathrm{kg}^{-1}$ & 240 & 290 & 340 \\
\hline
\end{tabular}

'Metodologia de extração e determinação: Para o pH em água utilizou-se a relação solo:solucẫo de 1:2,5, determinando-o na suspensão. $0 \mathrm{P}$ e K foram extraídos pelo método de Mehlich1 e, Ca, Mg e Al trocáveis por $\mathrm{KCl} 1 \mathrm{~mol} \mathrm{~L}$, e H+Al pelo acetato de cálcio $0,5 \mathrm{~mol} \mathrm{~L}^{-1}$. $0 \mathrm{~N}$ no solo foi obtido por digestão sulfúrica e determinado pelo método Kjeldahl.

O delineamento experimental utilizado foi o de blocos ao acaso com quatro repetiçóes. Os tratamentos consistiram de cinco clones de eucalipto provenientes de diferentes locais de seleção, mas que já estão sendo utilizados por algumas empresas no estado do Pará: 03 - Eucalyptus grandis x $E$. urophylla (Minas Gerais), 07 - E. grandis $x$ E. pellita (Marabá/ Pará); 09 - E. grandis $x$ E. urophylla (Imperatriz/Maranhão), 11 - E. camaldulensis (Marabá/Pará), 32 - E. urophylla $\times$ E. camaldulensis (Minas Gerais). As parcelas experimentais foram compostas por 50 árvores cada no espaçamento $3 \times 3$ $\mathrm{m}$ (correspondente a 1111 plantas ha $\mathrm{a}^{-1}$ ), sendo cinco linhas com 10 plantas.

$\mathrm{Na}$ área de estudo, antes de floresta secundária com aproximadamente 10 anos, foi realizado corte e derrubada da vegetação. Posteriormente, foi efetuado o destocamento para o preparo do solo. Aproximadamente 15 dias anteriores ao plantio foi realizada subsolagem no espaçamento de três metros entre sulcos, com aplicaçáa simultânea de fosfato natural reativo na dosagem de e $0,42 \mathrm{t} \mathrm{ha}^{-1}$; em sequência foi feita a calagem a lanço em área total, na dosagem de 1,0 t ha $^{-1}$ de calcário dolomítico, necessária para atingir valor de $\mathrm{V}$ $=30 \%$, baseada no método da saturação por bases. Passados os 15 dias, foram abertas covas com dimensôes de 25 x 25 x $25 \mathrm{~cm}$, obedecendo-se o espaçamento de $3 \times 3 \mathrm{~m}$ nos sulcos de subsolagem. Em seguida foi realizada colocação das mudas e adubação de plantio com a aplicaçấo de $90 \mathrm{~g}$ cova $^{-1}$ da fórmula NPK (06-30-06) em covetas laterais as plantas. A recomendação de adubação e calagem foi feita a partir da interpretaçâo da análise do solo, conforme descritos por Barros et al. (2005), para a obtençấo de níveis de produtividades adequados para eucalipto, segundo os valores de $\mathrm{P}, \mathrm{K}, \mathrm{Ca}, \mathrm{Mg}$ e $\mathrm{N}$ no solo, sendo este último elemento calculado a partir dos valores de matéria orgânica. Apesar de recomendada, não foi realizada adubação de cobertura no período experimental. As mudas clonais foram adquiridas com 60 dias de idade. Durante o período de avaliação foram realizadas três capinas e um controle localizado de formigas cortadeiras.

Foram realizadas mediçóes de altura total e sobrevivência em duas épocas de coleta, aos cinco e 18 meses após o plantio. Mensurou-se o diâmetro à altura do peito (DAP a 1,3 m do solo) apenas na segunda coleta (18 meses). A altura foi medida com auxílio do Vertex ${ }^{\circ}$, medidor automático de altura por meio da tomada do ângulo formado entre a base do tronco e o topo da copa. O DAP foi calculado pela medida da circunferência à altura do peito com auxílio de fita métrica. A avaliação do desenvolvimento inicial, representado por altura e DAP, foi tomada em todas as 50 árvores de cada parcela, $100 \%$ dos indivíduos vivos. Para a avaliaçáo da porcentagem de sobrevivência foram consideradas as plantas mortas, as falhas e plantas secas.

A amostragem das folhas e solo foi realizada aos 18 meses após o plantio. Para fins de avaliação nutricional foliar foi realizada amostragem de acordo com a recomendação de Bellote e Silva (2005). Em cada parcela de 50 árvores foram amostrados seis indivíduos, retirando os galhos do terço médio e coletando-se as folhas 3, 4, 5 e 6 a partir do ápice e recém-maduras, totalizando uma amostra composta com 24 folhas por parcela experimental. Em meio às árvores escolhidas foram selecionadas, no mínimo, três árvores dominantes por amostra por expressar melhor o potencial de produtividade das espécies, atentando-se para o conceito de árvores dominantes,as quais são as 100 árvores de maior DAP por hectare. As folhas foram armazenadas em sacos de papel e conduzidas para laboratório e, posteriormente foram lavadas com água destilada, colocadas em estufa de circulação forçada a $75^{\circ} \mathrm{C}$ e moídas com peneira de $1 \mathrm{~mm}$ em moinho do tipo Willye.

Para a amostragem do solo com fins de avaliação da fertilidade foram coletadas as profundidades $0-10$ e 10-20 
$\mathrm{cm}$ na entrelinha seguindo um caminhamento aleatório dentro da parcela. De cada parcela foram retiradas cinco amostras simples por profundidade para formar uma composta, totalizando duas amostras compostas por unidade experimental, que foram secas ao ar e passadas em peneiras de $2 \mathrm{~mm}$ para as análises.

Todas as análises de planta e solo foram realizadas no Laboratório de Química do solo da Universidade Federal Rural da Amazônia. Os nutrientes determinados nas plantas foram N, P, K, Ca, Mg, Cu, Fe, Mn e Zn e os atributos da fertilidade do solo foram $\mathrm{pH}$ em água, $\mathrm{Al}$ trocável, $\mathrm{H}+\mathrm{Al}$, $\mathrm{N}, \mathrm{P}, \mathrm{K}, \mathrm{Ca}$ e $\mathrm{Mg}$ trocáveis, capacidade de troca de cátions (CTC a pH 7,0) e saturação por bases (V\%) e $\mathrm{MO}$ (matéria orgânica). As determinaçóes de macro e micronutrientes nas folhas foram realizadas seguindo a metodologia descrita por Malavolta et al. (1997) e as determinaçôes dos atributos da fertilidade do solo foram realizadas seguindo a metodologia descrita por Embrapa (1997).

Para as análises estatísticas foi utilizado software Statistica 9.0 (Statsoft 2009). Realizou-se o teste Shapiro-Wilk para determinaçáo da normalidade dos dados. Nos casos em que não foi verificada a distribuição normal, efetuou-se a transformação dos mesmos, utilizando para isso o inverso do número, a raiz quadrada, ou o inverso da raiz. Após esse procedimento, foi realizada a análise de variância com teste $\mathrm{F}(5 \%)$. As médias para todas as variáveis que sofreram efeito significativo foram comparadas pelo teste de Tukey a 5\%. Realizou-se também análise de correlação entre desenvolvimento inicial com a fertilidade do solo e os nutrientes foliares.

\section{RESULTADOS E DISCUSSÃO}

\section{Sobrevivência e desenvolvimento inicial}

Os clones apresentaram sobrevivência no campo acima de $89 \%$ nas duas épocas de avaliaçáo, sendo que dos cinco para os 18 meses ocorreu uma sensível redução do número de indivíduos para todos os materiais genéticos estudados (Tabela 2). Nos primeiros cinco meses após o plantio, os clones não apresentaram diferença estatística significativa quanto à sobrevivência. Entretanto, aos 18 meses, o clone 07 mostrou-se significativamente inferior à maioria dos outros materiais genéticos quanto a essa variável, sendo semelhante apenas ao clone 03 .

Os menores valores de sobrevivência para os clones $03 \mathrm{e}$ 07, que são materiais genéticos de E. grandis x E. urophylla, podem estar relacionados a dificuldades de adaptação para as condiçôes ambientais da regiâo do município de Moju ou indicar que a ausência de adubação de cobertura e a deficiência hídrica, comum na regiáo do estudo no segundo semestre do ano (Sousa 2006), foram mais limitantes ao desenvolvimento desses dois materiais genéticos.
Tabela 2 - Sobrevivência, altura e DAP de clones de eucalipto aos 5 e 18 meses após plantio em Moju, Pará.

\begin{tabular}{cccccc}
\hline Clone $^{1}$ & \multicolumn{3}{c}{ Sobrevivência (\%) } & \multicolumn{3}{c}{ Altura $(\mathrm{m})$} & DAP $(\mathrm{cm})$ \\
\hline & 5 meses & 18 meses & 5 meses & 18 meses & 18 meses \\
\hline 03 & 97,5 & $94,5 \mathrm{ab}$ & 0,72 & 8,49 & 7,7 \\
07 & 97 & $89,5 \mathrm{~b}$ & 1,02 & 8,33 & 7,5 \\
09 & 99,5 & $99,0 \mathrm{a}$ & 0,88 & 9,42 & 8,0 \\
11 & 100 & $99,5 \mathrm{a}$ & 1,02 & 9,92 & 7,5 \\
\hline 32 & 100 & $98,5 \mathrm{a}$ & 1,20 & 9,05 & 8,9 \\
\hline DMS & 4,58 & 8,69 & 0,66 & 2,79 & 2,61 \\
\hline $\mathrm{F}$ & $1,94^{\text {ns }}$ & $3,35^{\star}$ & $1,48^{\text {ns }}$ & $0,55^{\mathrm{ns}}$ & $1,33^{\text {ns }}$ \\
CV(\%) & 2,2 & 5,9 & 29,8 & 15 & 15,6 \\
\hline
\end{tabular}

$103-E$. grandis $\times$ E. urophylla, $07-E$. grandis $\times$ E. pellita, $09-$ E.s grandis $\times E$. urophylla, 11 - E. camaldulensis e $32-$ E. Urophylla $\times$ E. camaldulensis. Médias seguidas pela mesma letra na coluna não diferem entre si pelo teste de Tukey a $5 \%$ ${ }_{*} \mathrm{e}$ ns, significativo e não significativo, respectivamente, pelo teste $F(0,05)$. DMS diferença mínima significativa. CV (\%) - Coeficiente de variação.

As sobrevivências dos clones observadas neste trabalho são consideradas satisfatórias, uma vez que não ultrapassaram $3 \%$ de mortalidade aos cinco meses e $11 \%$ aos 18 meses, evidenciando um bom estabelecimento inicial desses materiais genéticos no campo, mesmo estes sendo provenientes de diferentes locais de seleção. Os valores de sobrevivência encontrados nesse estudo são semelhantes aos observados por Souza et al. (2004), que avaliando cinco clones híbridos de Eucalyptus grandis x E. urophylla com 4 anos de idade, na região central do Estado do Amazonas, também sobre Latossolo Amarelo distrófico e apenas com adubaçáo de plantio, constataram que as sobrevivências variaram de 92 a $100 \%$. Sáo semelhantes também à sobrevivência média de $92 \%$ observadas por Tonini et al. (2006) para clones de $E$. grandis $\mathrm{x}$ E. urophylla aos seis anos, plantados no Estado de Roraima sobre Argissolo Vermelho Amarelo distrófico.

Em relação à altura, não houve diferenças significativas entre os clones nas duas épocas de avaliação, sendo que, considerando todos os clones, a média das alturas aos cinco meses foi de $0,96 \mathrm{~m}$ e aos 18 meses de $9,04 \mathrm{~m}$. As médias de altura de todos os clones deste trabalho foram superiores as encontradas por Queiroz et al. (2009) em $E$. grandis, E. urophylla, E. camaudulensis e E, pellita, avaliados aos 18 meses após o plantio no Rio de Janeiro, os quais apresentaram alturas variando de 2,7 a 5,2 m, valor mínimo e máximo, respectivamente. Segundo esses autores, plantas que apresentam rápido crescimento em altura nos primeiros meses de idade, possuem vantagens competitivas em relação à vegetaçáo espontânea. Este aspecto reduz a necessidade de capinas na área, diminuindo o custo de manutenção no plantio.

O DAP também não variou significativamente em função dos tratamentos aos 18 meses, ficando a média geral dos 
clones correspondente a 7,92 cm. Esses resultados foram semelhantes aos encontrados no nordeste brasileiro por Drumond et al. (1998), nos tabuleiros costeiros do Estado de Sergipe, e Coutinho et al. (2004), na zona da mata do estado de Pernambuco, para espécies de eucalipto com 30 e 12 meses, respectivamente, sendo que esses autores observaram uma variaçáo bem pequena de diâmetro entre os materiais genéticos avaliados.

\section{Fertilidade do solo}

$\mathrm{Na}$ profundidade $0-10 \mathrm{~cm}$, foi detectada diferença significativa entre as parcelas de cada tratamento apenas para os valores de Ke CTC (Tabela 3). Na profundidade de 10-20 $\mathrm{cm}$, além do potássio, o $\mathrm{Ne}$ Ca tiveram variaçóes significativas em função dos tratamentos.

O maior teor de $\mathrm{K}$ na camada de $0-10 \mathrm{~cm}$ foi observado no solo sob o clone 03 , o qual diferiu dos valores mais baixos apresentados pelos clones 07 e 09 . A maior concentraçáo de $\mathrm{K}$ no solo sob o clone 03 indica a sua menor extraçáo do nutriente até os 18 meses Tal efeito é confirmado na concentração foliar (Tabela 4), onde o valor desse elemento é equivalentemente baixo. Essa correspondência não ocorre

Tabela 3 - Fertilidade de Latossolo Amarelo textura média, nas profundidades de 0-10 e 10-20 cm, e correlação entre a fertilidade do solo da camada de 0-20 cm e o desenvolvimento inicial de cinco aos de 18 meses após o plantio em Moju, Pará.

\begin{tabular}{|c|c|c|c|c|c|c|c|c|c|c|c|c|}
\hline \multirow[t]{2}{*}{ Clone } & & \multirow[t]{2}{*}{$\mathrm{pH}$} & MO & $\mathrm{N}$ & \multirow{2}{*}{ 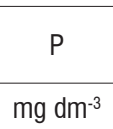 } & K & $\mathrm{Ca}$ & $\mathrm{Mg}$ & $\mathrm{Al}$ & $\mathrm{H}+\mathrm{Al}$ & $\begin{array}{c}\text { CTC } \\
(\mathrm{pH} 7,0)\end{array}$ & \multirow{2}{*}{$\begin{array}{l}\mathrm{V} \\
\%\end{array}$} \\
\hline & & & \multicolumn{2}{|c|}{$\mathrm{g} \mathrm{kg}^{-1}$} & & \multicolumn{6}{|c|}{$\mathrm{cmol}_{\mathrm{c}} \mathrm{dm}^{-3}$} & \\
\hline & & \multicolumn{11}{|c|}{$0-10 \mathrm{~cm}$} \\
\hline 03 & & 5,64 & 13,7 & 1,28 & 7,91 & $0,08 \mathrm{a}$ & 3,4 & 0,72 & 0,23 & 4,39 & $8,55 a b$ & 48,82 \\
\hline 07 & & 4,98 & 8,08 & 1,5 & 4,9 & $0,03 \mathrm{~b}$ & 1,6 & 0,69 & 0,18 & 4,49 & $6,80 \mathrm{~b}$ & 34,07 \\
\hline 09 & & 4,94 & 15,64 & 1,28 & 5,12 & $0,03 b$ & 2,54 & 0,66 & 0,7 & 6,912 & $10,16 \mathrm{a}$ & 32,34 \\
\hline 11 & & 5,91 & 11,37 & 1,6 & 5,44 & $0,05 a b$ & 2,36 & 0,6 & 0,2 & 4,718 & $7,72 \mathrm{ab}$ & 39,4 \\
\hline 32 & & 5,17 & 21,2 & 1,39 & 5,27 & $0,04 a b$ & 1,95 & 1,37 & 0,48 & 5,222 & $8,59 a b$ & 38,57 \\
\hline DMS & & 1,73 & 17,81 & 0,66 & 3,97 & 0,041 & 2,63 & 1,73 & 0,7 & 3,04 & 2,56 & 28,97 \\
\hline $\mathrm{F}$ & & $1,24^{\mathrm{ns}}$ & $1,16^{\text {ns }}$ & $0,89 \mathrm{~ns}$ & $1,95^{\mathrm{ns}}$ & $5,34^{*}$ & $2,17^{\mathrm{ns}}$ & $2,91^{\mathrm{ns}}$ & $0,09^{\text {ns }}$ & $2,31^{\text {ns }}$ & $4,74^{*}$ & $0,99^{\text {ns }}$ \\
\hline \multirow[t]{2}{*}{ CV (\%) } & & 14 & 29 & 19,75 & 33 & 15 & 6,3 & 8,2 & 9,3 & 15 & 18 & 31 \\
\hline & & \multicolumn{11}{|c|}{$10-20 \mathrm{~cm}$} \\
\hline 03 & & 5,43 & 14,29 & $1,28 \mathrm{a}$ & 7,08 & $0,07 \mathrm{a}$ & $2,40 a$ & 0,37 & 0,3 & 4,62 & 7,48 & 38,28 \\
\hline 07 & & 5,04 & 12,8 & $1,50 \mathrm{a}$ & 4,13 & $0,02 b$ & $1,21 b$ & 0,88 & 0,4 & 4,72 & 6,84 & 30,96 \\
\hline 09 & & 4,79 & 12,28 & $1,28 \mathrm{a}$ & 4,89 & $0,03 b$ & $1,12 b$ & 0,66 & 1,05 & 6,96 & 8,78 & 20,91 \\
\hline 11 & & 5,02 & 18,62 & $1,39 a$ & 4,68 & $0,03 \mathrm{~b}$ & $1,04 \mathrm{~b}$ & 0,83 & 0,5 & 4,87 & 6,29 & 22,98 \\
\hline 32 & & 4,74 & 19,27 & $0,75 b$ & 6,31 & $0,02 b$ & $2,03 \mathrm{~b}$ & 0,61 & 0,73 & 5,1 & 7,77 & 31,9 \\
\hline DMS & & 1,09 & 10,01 & 0,48 & 4,82 & 0,035 & 0,3 & 1,99 & 0,96 & 2,69 & 3,46 & 23,99 \\
\hline $\mathrm{F}$ & & $1,28^{\text {ns }}$ & $2,17^{\text {ns }}$ & $7,12^{*}$ & $1,32^{\mathrm{ns}}$ & $4,1^{*}$ & $3,49^{*}$ & $1,89^{\text {ns }}$ & $2,12^{\mathrm{ns}}$ & $2,64^{\text {ns }}$ & $1,52^{\mathrm{ns}}$ & $1,76^{\text {ns }}$ \\
\hline \multirow[t]{2}{*}{ CV (\%) } & & 10 & 33 & 25,84 & 38 & 6,6 & 9,8 & 9 & 7,5 & 25 & 21 & 41 \\
\hline & & \multicolumn{11}{|c|}{ Coeficientes de correlação $(0-20 \mathrm{~cm})$} \\
\hline \multirow[t]{2}{*}{03} & Altura & $-0,54$ & $-0,94$ & $-0,09$ & $-0,71$ & $-0,16$ & $-0,18$ & $-0,52$ & 0,8 & 0,66 & 0,84 & $-0,45$ \\
\hline & DAP & $-0,74$ & $-0,79$ & $-0,23$ & $-0,68$ & $-0,35$ & $-0,48$ & $-0,67$ & $0,96^{\star}$ & 0,88 & 0,74 & $-0,72$ \\
\hline \multirow[t]{2}{*}{07} & Altura & $-0,18$ & $-0,46$ & $-0,26$ & $-0,68$ & $0,98^{*}$ & 0,21 & $-0,78$ & 0,17 & $-0,11$ & $-0,62$ & $-0,32$ \\
\hline & DAP & $-0,1$ & $-0,56$ & $-0,27$ & $-0,77$ & $0,97^{\star}$ & 0,34 & $-0,86$ & 0,1 & $-0,25$ & $-0,7$ & $-0,19$ \\
\hline \multirow[t]{2}{*}{09} & Altura & 0,38 & 0,83 & 0,64 & 0,38 & $-0,09$ & $-0,76$ & 0,76 & $-0,01$ & $-0,47$ & $-0,44$ & 0,45 \\
\hline & DAP & 0,62 & 0,86 & 0,78 & 0,38 & $-0,15$ & $-0,58$ & 0,58 & $-0,24$ & $-0,15$ & $-0,11$ & 0,13 \\
\hline \multirow[t]{2}{*}{11} & Altura & 0,72 & $-0,73$ & 0,15 & $-0,43$ & 0,51 & 0,22 & 0,55 & 0,46 & 0,3 & 0,79 & 0,13 \\
\hline & DAP & 0,78 & $-0,95$ & 0,51 & $-0,08$ & 0,47 & 0,29 & 0,6 & 0,48 & 0,29 & 0,86 & 0,2 \\
\hline \multirow[t]{2}{*}{32} & Altura & $-0,8$ & $-0,24$ & $-0,96^{*}$ & 0,05 & $-0,82$ & $-0,69$ & 0,7 & 0,84 & $-0,6$ & $-0,33$ & 0,32 \\
\hline & DAP & $-0,02$ & $-0,03$ & $-0,54$ & $-0,13$ & $-0,84$ & $-0,7$ & 0,24 & 0,84 & $-0,99 *$ & $-0,89$ & $-0,43$ \\
\hline
\end{tabular}

${ }^{1} 03$ - E. grandis $\times$ E. urophylla, 07-E. grandis $\times$ E. pellita, $09-$ E.s grandis $\times$ E. urophylla, $11-$ E. camaldulensis e $32-E$. urophylla $\times$ E. camaldulensis. Médias seguidas pela mesma letra na coluna não diferem estatisticamente entre si pelo teste de Tukey a 5\%. ns e *, não significativo e significativo, respectivamente a $5 \%$. DMS - diferença mínima significativa. CV (\%) - coeficiente de variação. 
Tabela 4 - Teores de macro e micronutrientes nos tecidos foliares e correlação entre os nutrientes nas folhas com o desenvolvimento inicial de cinco clones de eucalipto aos 18 meses após plantados sobre Latossolo Amarelo distrófico textura média de Moju, Pará.

\begin{tabular}{|c|c|c|c|c|c|c|c|c|c|c|}
\hline \multirow{2}{*}{ Clone $^{2}$} & & $\mathrm{~N}$ & $P$ & K & $\mathrm{Ca}$ & $\mathrm{Mg}$ & $\mathrm{Cu}$ & $\mathrm{Fe}$ & $\mathrm{Mn}$ & Zn \\
\hline & & \multicolumn{5}{|c|}{$\mathrm{g} \mathrm{kg}^{-1}$} & \multicolumn{4}{|c|}{$\mathrm{mg} \mathrm{kg}^{-1}$} \\
\hline \multicolumn{2}{|l|}{03} & $11,83 \mathrm{a}$ & 0,68 & $5,14 \mathrm{~b}$ & $1,94 \mathrm{c}$ & $0,75 b$ & 6,4 & $75,0 \mathrm{~b}$ & 168 & $9,75 \mathrm{cb}$ \\
\hline \multicolumn{2}{|l|}{07} & $10,73 a b$ & 0,82 & $3,97 \mathrm{~b}$ & $1,98 \mathrm{c}$ & $0,80 a b$ & 3,88 & $94,5 \mathrm{ab}$ & 219 & $6,25 c$ \\
\hline \multicolumn{2}{|l|}{09} & $10,0 \mathrm{~b}$ & 0,81 & $4,96 \mathrm{~b}$ & $2,18 \mathrm{c}$ & $0,80 \mathrm{ab}$ & 7,05 & $60,5 \mathrm{~b}$ & 268 & $20,50 a$ \\
\hline \multicolumn{2}{|l|}{11} & $11,10 a b$ & 0,66 & $7,67 \mathrm{a}$ & $3,99 \mathrm{~b}$ & $0,60 \mathrm{~b}$ & 7,8 & $148 \mathrm{a}$ & 149 & $14,50 \mathrm{ab}$ \\
\hline \multicolumn{2}{|l|}{32} & $11,0 a b$ & 0,9 & $6,84 \mathrm{a}$ & $5,04 \mathrm{a}$ & $1,25 \mathrm{a}$ & 5,45 & $54,75 \mathrm{~b}$ & 211 & $19,35 \mathrm{a}$ \\
\hline \multicolumn{2}{|l|}{ DMS } & 1,47 & 0,64 & 1,51 & 0,74 & 0,49 & 5,69 & 61,1 & 209,43 & 7,37 \\
\hline \multicolumn{2}{|l|}{$\mathrm{F}$} & $3,65^{\star}$ & $0,49^{\text {ns }}$ & $19,92^{*}$ & $72,26^{\star}$ & $4,88^{\star}$ & $1,45^{\mathrm{ns}}$ & $7,71^{*}$ & $1,0^{\text {ns }}$ & $14,34^{*}$ \\
\hline \multicolumn{2}{|l|}{ CV (\%) } & 8,78 & 23,7 & 26,5 & 14,66 & 15,5 & 20,2 & 40,3 & 48,8 & 45,12 \\
\hline & & \multicolumn{9}{|c|}{ Coeficientes de Correlação } \\
\hline \multirow[t]{2}{*}{03} & Altura & 0,56 & 0,68 & 0,04 & 0,17 & 0,71 & 0,02 & $-0,94$ & $-0,61$ & 0,53 \\
\hline & DAP & 0,77 & 0,86 & 0,07 & $-0,08$ & 0,55 & 0,04 & $0,99 *$ & $-0,56$ & 0,29 \\
\hline \multirow[t]{2}{*}{07} & Altura & 0,02 & 0,81 & 0,7 & $0,99 *$ & $-0,79$ & 0,88 & 0,2 & 0,88 & 0,79 \\
\hline & DAP & 0,06 & 0,87 & 0,77 & $0,97^{*}$ & $-0,7$ & 0,91 & 0,29 & 0,92 & 0,83 \\
\hline \multirow[t]{2}{*}{09} & Altura & 0,28 & 0,05 & 0,67 & $-0,03$ & $-0,75$ & $-0,01$ & 0,61 & $-0,77$ & 0,89 \\
\hline & DAP & 0,6 & 0,36 & 0,5 & 0,16 & $-0,7$ & 0,28 & 0,85 & $-0,93$ & 0,73 \\
\hline \multirow[t]{2}{*}{11} & Altura & $-0,12$ & $-0,95$ & $-0,23$ & $-0,87$ & 0,15 & $0,98^{*}$ & 0,38 & $-0,22$ & $-0,07$ \\
\hline & DAP & $-0,31$ & $-0,76$ & 0,05 & $-0,97^{\star}$ & 0,01 & 0,82 & 0,6 & $-0,59$ & 0,14 \\
\hline \multirow[t]{2}{*}{32} & Altura & $-0,96$ & $-0,73$ & 0,01 & 0,67 & $-0,56$ & 0,4 & $-0,47$ & $-0,13$ & $-0,7$ \\
\hline & DAP & $-0,67$ & $-0,11$ & $-0,55$ & 0,32 & 0,16 & 0,09 & $-0,73$ & $-0,46$ & $-0,01$ \\
\hline
\end{tabular}

${ }^{1}$ Metodologia de extração e determinação: No extrato obtido por digestão nitroperclórica do material vegetal, foram quantificados os teores de $P$ por colorimetria, K por fotometria de chama, Ca, Mg, e micronutrientes por espectrofotometria de absorção atômica e N por digestão sulfúrica e determinado pelo método Kjeldahl.203 - E. grandis x E. urophylla, $07-E$. grandis $\times$ E. pellita, 09 - E.s grandis x E. urophylla, 11 - E. camaldulensis e 32 - E. urophylla x E. camaldulensis. Médias seguidas pela mesma letra na coluna não diferem estatisticamente entre si pelo teste de Tukey a $5 \%$. ns e * não significativo e significativo, respectivamente a $5 \%$. DMS - diferença mínima significativa. C.V. (\%) - coeficiente de variação.

nos clones 07 e 09 , os quais apresentam valores baixos de $\mathrm{K}$ tanto no solo como nas folhas.

$\mathrm{O}$ clone 07 e 09 foram os únicos que se diferenciaram quanto a CTC na camada de $0-10 \mathrm{~cm}$, sendo do clone 09 a maior média apresentada. Provavelmente, esse resultado está relacionado à baixa absorção dos macronutrientes, principalmente Ca pelo clone 09 o que manteria elevada a capacidade de troca de cátions no solo.

O teor de nitrogênio na camada 10-20 cm foi estatisticamente menor no clone 32, resultado indicativo de maior absorção de $\mathrm{N}$ por esse clone, o que pode ser justificado pelo fato desse material genético apresentar uma elevada demanda de nutrientes nas fases iniciais de seu desenvolvimento (Camargo et al. 2004). Nessa mesma profundidade, para $\mathrm{K}$ e $\mathrm{Ca}$, o clone 03 apresentou médias significativamente superiores aos demais materiais, os quais não diferiram entre si.
De maneira geral, constataram-se poucas correlaçóes estatisticamente significativas entre a fertilidade do solo e o desenvolvimento inicial dos cones de eucalipto (Tabela 3). Esse resultado assemelha-se ao encontrado por Mushaka (1998), o qual não observou correlação entre o pH, $\mathrm{MO}, \mathrm{P}$ e $\mathrm{K}$ do solo com a produtividade de $E$ camaldulensis no Zimbabwe, África do Sul.

No clone 03, o Al correlacionou-se positivamente com o DAP das folhas. Esse resultado corrobora os obtidos por Bellote e Ferreira (1993) em plantações de E. grandis com 3 anos de idade na Região dos Cerrados do Estado de São Paulo. Segundo esses autores, como espécies de E. grandis são tolerantes ao $\mathrm{Al}$, quanto maior o crescimento das árvores, mais $\mathrm{Al}$ é passivamente absorvido pelas raízes.

Os teores de $\mathrm{K}$ no solo associaram-se positivamente com a altura e crescimento do clone 07 . Resultados como esses são esperados, uma vez que a absorção de K favorece o crescimento do eucalipto (Silva et al. 2002), devido a essencialidade desse 
nutriente nos processos de controle osmótico, fotossíntese e transporte de fotoassimilados, além de estar relacionado com a ativação de cerca de 50 tipos de enzimas.

Os teores de $\mathrm{N}$ no solo correlacionaram-se negativamente com a altura do clone 32. Segundo Santana et al. (1999) são freqüentes as correlaçóes inversas entre os teores de nutrientes no solo e o desenvolvimento do eucalipto. Segundo esses autores tal falta de correlaçáo está relacionada à baixa fertilidade dos sítios estudados, fazendo com que o conteúdo de nutrientes das árvores represente elevada proporção do capital total de nutrientes do sítio. Tal afirmativa pode ser confirmada neste estudo uma vez que os teores de $\mathrm{N}$ no solo estáo muito abaixo dos requeridos para o eucalipto segundo Barros et al. (2005).

Independentemente dos clones e profundidades, os atributos químicos do solo $\mathrm{pH}, \mathrm{P}, \mathrm{Ca}, \mathrm{Mg}$ e V apresentaram valores compatíveis para o pleno desenvolvimento dos materiais genéticos de eucalipto estando, de acordo com Sgarbi (2002), situados em níveis de fertilidade médios a altos. Ainda de acordo com o trabalho desse autor, os teores de MO para todos os clones apresentaram-se de baixos a médios e os de CTC todos baixos. A reduçáo inicial da $\mathrm{MO}$ do solo se deve à retirada da floresta secundária para a implantação do plantio de eucalipto, expondo o solo a radiaçáo e provocando, assim, aumento da oxidação da matéria orgânica, fato que será amenizado com o inicio da ciclagem do plantio, que inicia próximo aos quatro anos (Gama-Rodrigues et al. 2009).

Nas parcelas de todos os clones os teores de $\mathrm{Al}$, apesar de não apresentarem neutralizaçáo total pela ação da calagem, situaram-se em níveis baixos, o que provavelmente não está promovendo problemas com a acidez trocável às arvores, principalmente quando se considera que a maioria das espécies florestais apresenta tolerância a elevados teores desse elemento no solo (Gonçalves 1995).

Os teores de P, Ca e Mg no solo nas parcelas de todos os clones, em conformidade com a revisáo feita por Barros et al. (2005), apresentaram-se dentro da faixa adequada de manutençáo do plantio de eucalipto para obtençáo de elevada produtividade de madeira, próximo a $60 \mathrm{~m}^{3} \mathrm{ha}^{-1} \mathrm{ano}^{-1}$. Esses resultados contrastam com as concentraçóes nos tecidos foliares (Tabela 4), que de maneira geral apresentaram-se abaixo das faixas adequadas. Diferentemente do ocorrido para os outros elementos, os teores de $\mathrm{K}$ e $\mathrm{N}$ no solo situaram-se em níveis baixos, sendo que, em relação ao potássio, seu valor no solo pode limitar as espécies a produtividades próximas a $10 \mathrm{~m}^{3} \mathrm{ha}^{-1}$ ano $^{-1}$.

Esses resultados são importantes porque demonstram a necessidade das correçóes e adubaçóes de cobertura que devem ser realizadas para o adequado desenvolvimento de um povoamento de eucalipto. Neste trabalho foi realizada a calagem e fosfatagem em pré-plantio, além da adubação com NPK 06-30-06 no plantio que fornece o fósforo solúvel em maior concentração que $\mathrm{N}$ e K. A falta de adubaçôes de cobertura, na qual seriam fornecidos esses últimos dois nutrientes justifica os baixos níveis encontrados.

\section{Estado nutricional}

$\mathrm{O}$ teste $\mathrm{F}$ da análise de variância detectou diferença estatística significativa entre os clones para a concentração de $\mathrm{N}, \mathrm{K}, \mathrm{Ca}, \mathrm{Mg}, \mathrm{Cu}$, Fe e $\mathrm{Zn}$ nas folhas (Tabela 4). Tais resultados concordam com os obtidos por Macedo et al. (1996) e Santana et al. (1999). Estes autores observaram variaçôes nutricionais entre diferentes materiais genéticos de eucalipto plantados no mesmo local, sobre condiçóes uniformes de preparo do solo e adubaçáo. Para Wadt et al. (1999) essas variações são atribuídas às particularidades nutricionais de cada material genético, que podem estar relacionadas às variadas eficiência de utilização e capacidade de aquisição dos nutrientes.

Somente os clones 03 e 09 apresentaram diferenças estatísticas nas concentrações de $\mathrm{N}$ nas folhas, sendo do primeiro clone a maior média. Essa diferença entre os clones, ambos híbridos de E. grandis x E. urophylla, pode estar relacionada as suas respectivas regióes de seleção, o clone 03 é proveniente do Estado de Minas Gerais e o clone 09 do Maranhão. Variaçốes dos aspectos nutricionais entre clones de mesma espécie, mas com procedências diferentes, têm sido observadas nas literaturas (Caldeira et al. 2002; Santana et al. 2002). No presente estudo observou-se que o material genético selecionado em Minas Gerais, mais distante das condiçôes da regiấo do nordeste paraense, apresentou melhores teores nutricionais de $\mathrm{N}$. Tal resultado pode estar relacionado ao menor ou maior nível de melhoramento genético aplicado aos clones.

As concentraçôes $\mathrm{K}$ nas folhas foram significativamente maiores nos clones 11 e 32 . As maiores concentraçôes de $\mathrm{K}$ encontradas nesses clones, dois materiais de E. camaldulensis, diferem dos encontrados por Queiroz et al. (2009), em teste com plantios de 18 meses no Rio de Janeiro, onde clones de E. grandis apresentaram concentraçôes de $\mathrm{K}$ nas folhas superiores à E. camaldulensis. Segundo Camargo et al. (2004), em relação à outras espécies de eucalipto, E. camaldulensis apresenta uma elevada demanda de nutrientes no campo e um amplo sistema radicular, o que pode justificar os maiores teores de $\mathrm{K}$ nos clones 11 e 32. Como o K é predominantemente absorvido por difusão, processo lento, um maior volume de raízes favorece o contato com o nutriente. Reis et al. (2006), trabalhando com diferentes clones de Eucalyptus no norte do Estado da Bahia, observou que E. camaldulensis $\mathrm{x}$ Eucalyptus spp. apresentou um maior crescimento do sistema radicular em relação a clones de $E$. grandis x E. urophylla. Para esses autores essa característica favoreceu uma melhor capacidade na 
absorção de água e nutrientes, o que torna a espécie bastante adaptável a diversos ambientes.

Para as concentraçóes de $\mathrm{Ca}$, o clone 32 apresentou maior média em relação ao 11 , sendo que esses dois materiais foram superiores aos demais que não apresentaram variaçôes significativas do nutriente entre si. Esse resultado evidenciou diferença entre o clone híbrido $E$. camaldulensis $\mathrm{x}$ E. urophylla e o clone simples E. camaldulensis. Segundo Bison et al. (2009), geralmente clones de híbridos interespecíficos tendem a apresentar melhor capacidade de adaptaçáo à diferentes regiôes, o que é devido a combinaçôes de características favoráveis dos materiais genéticos componentes da hibridação. Assim, tal fato pode também influenciar o estado nutricional dos clones.

O clone 32 apresentou concentração de $\mathrm{Mg}$ nas folhas, estatisticamente superior apenas aos materiais 03 e 11 . No caso desse nutriente, a variaçáo encontrada pode ser atribuída às diferenças entre espécies, híbridos e local de seleção. Segundo Faria et al. (2008) além das variaçôes resultantes das diferentes capacidades de absorção de cada material genético, a interação genótipo-ambiente pode influenciar o teor de nutrientes nos Eucalyptus.

Em relaçáo aos micronutrientes $\mathrm{Fe}$ e $\mathrm{Zn}$, os teores foram bastante variados entre os clones evidenciando uma absorção muito diferenciada entre os materiais genéticos. Maiores quantidades de Fe foram observadas nas folhas do clone 11 , os outros materiais apresentaram-se significativamente inferiores a esse tratamento, com exceção do clone 07 que teve valores estatisticamente intermediários. Os clones 07 e 11 são provenientes de seleção no Estado do Pará. A semelhança e proximidade dos solos de onde esses materiais foram provenientes, com o solo do presente estudo, em relação aos teores de Fe, geralmente Latossolos com elevado teores de óxidos de ferro, pode estar influenciando no comportamento do clone.

As concentraçôes de $\mathrm{Zn}$ nas folhas foram significativamente superiores nos clones 32 e 09 , que diferiram das menores médias do 03 e 07; o clone 11 apresentou semelhança tanto com os tratamentos superiores quanto com inferiores. A baixa concentraçáo de $\mathrm{Zn}$ no clone 07 , além de outros nutrientes como $\mathrm{K}$ e Ca nesse material genético, pode indicar uma possível limitação nutricional desse clone às características do local de estudo.

Considerando as correlaçóes das concentraçôes de nutrientes nas folhas e o crescimento das árvores, observaramse correlaçóes significativas para algumas variáveis nos clones 03, 07 e 11 (Tabela 4).

Os teores de Fe nas folhas se correlacionaram positivamente com o DAP do clone 03. A funçáo desse nutriente na cadeia de transporte de elétrons da fotossíntese provavelmente explica essa relação positiva.

As concentrações de Ca nas folhas do clone 07 se correlacionaram positivamente tanto para altura como para o DAP. Essa relaçáo confirma o papel do Ca na manutenção da integridade funcional da plasmalema e a importância desse nutriente para o desenvolvimento da árvore, uma vez que segundo Faria et al. (2002) o Ca é o elemento em maior quantidade no tronco.

Observou-se correlação positiva do $\mathrm{Cu}$ das folhas com a altura do clone 11. Mushaka (1998) também observou correlação positiva do Cu foliar e altura de E. camaldulensis entre zero e 4 anos de idade. Diferentemente do que ocorreu no clone 07 , houve correlação negativa entre o Ca nas folhas e o DAP do clone 11. Correlaçôes negativas entre o teor de Ca nas folhas e o desenvolvimento de Eucalyptus spp. tem sido observadas na literatura (Rocha et al. 2008). Segundo Bellote e Silva (2005), tal fato é resultante do efeito de diluiçáo que o crescimento da árvore provoca nas quantidades desse nutriente.

Considerando as literaturas pertinentes a faixas adequadas da concentração de nutrientes em folhas de Eucalyptus, os cinco clones estudados no presente trabalho apresentaram deficiência nutricional para a maioria dos macronutrientes (Tabela 4). Como exceção está a concentração de Ca para o clone 32 que se enquadra na faixa nutricional adequada apresentada por Malavolta et al. (1997), situada entre 5 a $6 \mathrm{~g} \mathrm{~kg}^{-1}$, que diz respeito a povoamentos de E. grandis com alta produtividade de madeira. Tal resultado evidencia que em relação às quantidades de $\mathrm{Ca}$ a calagem realizada em préplantio foi eficiente para suprir as necessidades nutricionais do clone 32 até os 18 meses. Neste clone, o P também situou-se dentro da faixa adequada apresentada por Gonçalves (1995), compreendida entre 0,9 a 1,3 $\mathrm{g} \mathrm{kg}^{-1}$, para espécies de Eucalyptus mais plantadas do Brasil.

Os micronutrientes, de forma geral, apresentaram-se dentro das faixas nutricionais adequadas. No entanto, é importante ressaltar que existem amplas variaçôes nas interpretaçôes da análise foliar em relação aos micronutrientes, principalmente quanto ao Fe e Mn (Gonçalves 1995).

As concentraçôes baixas de macronutrientes e alguns micronutrientes nas folhas dos clones podem estar relacionadas à falta da adubação de manutenção como foi explicado anteriormente. Outro fator que pode explicar os baixos valores dos elementos é a deficiência hídrica no solo, apresentada normalmente entre os meses de agosto a outubro no município de Moju, a qual possivelmente está restringindo a absorção de nutrientes pelo sistema radicular. A disponibilidade hídrica no solo é fator primordial para extraçáo de nutrientes, e tem maior importância em nutrientes absorvidos pelo mecanismo de fluxo de massa, como o N (Sgarbi 2002). 
Considerando as médias das concentraçôes foliares de nutrientes, os clones de Eucalyptus apresentaram a seguinte ordem decrescente para os macronutrientes: $\mathrm{N}>\mathrm{K}>\mathrm{Ca}>$ $\mathrm{Mg}>\mathrm{P}$. Da mesma forma, os micronutrientes apresentaram-se na ordem: $\mathrm{Mn}>\mathrm{Fe}>\mathrm{Zn}>\mathrm{Cu}$. Este padrão foi semelhante ao encontrado por Macedo et al. (1996) para oito espécies de Eucalyptus com 36 meses de plantadas em Cuiabá, Mato Grosso.

Foi possível também, identificar grupos de clones com diferentes padróes de absorçáo de macronutrientes. Os clones 03 e 32, ambos provenientes do Estado de Minas Gerais, apresentaram as concentraçôes nas folhas na sequência $\mathrm{N}>\mathrm{K}$ $>\mathrm{Ca}>\mathrm{Mg}>\mathrm{P}$. Os clones 07, 09 e 11, materiais do Estado do Pará e Maranhão, tiveram a ordem $\mathrm{N}>\mathrm{K}>\mathrm{Ca}>\mathrm{P}>\mathrm{Mg}$. Tais padróes indicam, pelo menos inicialmente, que os materiais genéticos da Amazônia oriental, e os vindos do sudeste do país, diferem quanto a absorção dos elementos $\mathrm{Mg}$ e $\mathrm{P}$, o que pode implicar em manejo diferenciado das adubaçóes. Para os micronutrientes não houve essa diferenciação.

\section{CONCLUSÕES}

A sobrevivência dos clones variou apenas aos 18 meses. $\mathrm{O}$ desenvolvimento inicial (altura e $\mathrm{DAP}$ ) não variou nos períodos avaliados.

A utilização de diferentes materiais genéticos alterou de forma diferente a fertilidade do solo.

O estado nutricional dos clones de eucalipto, avaliados pela concentração de nutrientes foliares, variou em função do material genético.

Ocorreram poucas correlaçóes entre as variáveis de nutrição, fertilidade e desenvolvimento.

\section{BIBLIOGRAFIA CITADA}

ABRAF. 2010. Anuário Estatístico da ABRAF 2010: ano base 2009. Associação Brasileira de Produtores de Florestas Plantadas. Brasília, 2010. 113pp.

Barros, N.F.; Neves, J.C.L.; Novais, R.F. 2005. Recomendação de fertilizantes minerais em plantios de eucalipto, p.135-165. In: Gonçalves, J. L. M.; Benedetti. (Eds.). Nutrição e fertilização florestal. v.2. Instituto de Pesquisas Florestais, Piracicaba, São Paulo.

Bellote, A.F.J.; Ferreira, C.A. 1993. Nutrientes minerais e crescimento de árvores adubadas de Eucalyptus grandis, na região do cerrado, no Estado de São Paulo. Boletim Pesquisa Florestal, 26/27: 17-65.

Bellote, A.FJ.; Silva, H.D. 2005. Técnicas de amostragem e avaliaçôes nutricionais em plantios de Eucalyptus spp, p.105-133. In: Gonçalves, J. L. M.; Benedetti (Eds.). Nutrição e fertilização florestal. v.2. Piracicaba: Instituto de Pesquisas e Estudos Florestais, Piracicaba, São Paulo.

Bison, O.; Ramalho, M.A.P.; Rezende, G.D.S.P. Aguiar, A.M.; Resende, M.D.V. 2009. Dialelo parcial entre clones de Eucalyptus camaldulensis e clones de E. urophylla, E. grandis e E. saligna. Revista Árvore, 33(3): 395-402.

Caldeira, M.V.W.; Rondon Neto, R.M.; Schumacher, M.V. 2002. Avaliaçáo da eficiência nutricional de três procedências australianas de acácia-negra (Acacia mearnsii De Wild.). Revista Árvore, 26(5): 615- 620.

Camargo, M.L.P.; Moraes, C.B.; Mori, E.S.; Guerrini, I.A.; Mello, E.J.; Oda, S. 2004. Consideraçôes sobre a eficiência nutricional em Eucalyptus. Cientifica, 32(2): 191-196.

Coutinho, J.L.B.; Santos, V.F.; Ferreira, R.L.C.; Nascimento, J.C.B. 2004. Avaliação do comportamento de espécies de Eucalyptus spp. Na zona da mata Pernambucana. I: Resultados do primeiro ano - 2001. Revista Árvore, 28(6): 771-775.

Drumond, M.A.; Lima, P.C.F.; Santos, R.A.V. 2003. Comportamento de algumas espécies/procedências de Eucalyptus no município de Lagoa Grande-PE. Brasil Florestal, 78: 75-80.

Drumond, M.A.; Oliveira, V.R.; Carvalho, O.M. 1998. Comportamento silvicultural de espécies e procedências de Eucalyptus na região dos tabuleiros costeiros do estado de Sergipe. Revista Arvore, 22(1): 137-142.

EMBRAPA. 1997. Centro Nacional de Pesquisa de Solos. Manual de métodos de análise de solo. 2.ed. Rio de Janeiro. 212pp.

EMBRAPA. 2006. Sistema Brasileiro de Classificação de Solos. 2.ed. Embrapa Solos, Rio de Janeiro. 306pp.

Faria, G.E.; Barros, N.F.; Cunha, V.L.P.; Martins, I.S.; Martins, R.C.C. 2008. Avaliação da produtividade, conteúdo e eficiência de utilizaçáo de nutrientes em genótipos de Eucalyptus spp. no vale do Jequitinhonha, MG. Ciência Florestal, 18(3): 363-373.

Faria, G.E.; Barros, N.F.; Novais, R.F.; Lima, J.C.; Teixeira, J.L. 2002. Produção e estado nutricional de povoamentos de Eucalyptus grandis, em segunda rotação, em resposta à adubação potássica. Revista Árvore, 26(5): 577-584.

Gama-Rodrigues, E.F.; Gama-Rodrigues, A.C.; Paulino, G.M., Franco, A.A. 2009. Atributos químicos e microbianos de solos sob diferentes coberturas vegetais no norte do estado do Rio de janeiro. Revista Brasileira de Ciência do Solo, 32: 21-1530.

Gonçalves, J.L.M. 1995. Recomendaçôes de adubaçấo para Eucalyptus, Pinus e Espécies Típicas da Mata Atlântica. Documentos Florestais, 15: 1-23.

Macedo, R.L.G.; Soares, R.V.; Soares, A.R. 1996. "Status" nutricional de Eucalyptus (na fase juvenil) introduzidos na baixada cuiabana, MT. Cerne, 2(2): 110 - 123.

Magalhães, L. M. S.; Blum, W. E. H. 1999. Concentração e distribuição de nutrientes nas folhas de espécies florestais, na Amazônia Ocidental. Floresta e Ambiente, 6(1): 127-137.

Malavolta, E.; Vitti, G.C.; Oliveira, S.A. 1997. Avaliaçâo do estado nutricional de plantas: princípios e aplicą̧ōes. POTAFOS, Piracicaba, São Paulo, 319 pp.

Mushaka, A. 1998. Relationship between growth, mineral nutrition and site factors for Eucalyptus camaldulensis (Dehnh) planted in some communal areas of Zimbabwe. Southern African Forestry Journal, 183: 59-65. 
Nemer, T.C., Jardim, F.C.S. 2004. An assesment of diameter growth rate in a population of Eschweilera odora (Poepp.) Miers with dbh $\geq 5 \mathrm{~cm}$ in a logged tropical rainforest, Moju, state of Pará, Brazil. Revista de Ciências Agrárias, 41: 77-88.

Queiroz, M.M.; Leles, P.S.S.; Oliveira Neto, S.N.; Ferreira, M.A. 2009. Comportamento de materiais genéticos de eucalipto em Paty do Alferes, RJ. Floresta e Ambiente, 16(1): 01 - 10.

Reis, G.G.; Reis, M.G.F.; Fontan, I. C.I.; Monte, M.A.; Gomes. A.N. Oliveira, C.H.R. 2006. Crescimento de raízes e da parte aérea de clones de híbridos de Eucalyptus grandis $\mathrm{x}$ Eucalyptus urophylla $\mathrm{e}$ de Eucalyptus camaldulensis x Eucalyptus spp submetidos a dois regimes de irrigação no campo. Revista Árvore, 30(6): 921-931.

Rocha, J. B.O.; Pozza, A.A.A.; Carvalho, J.G.; Silva, C.A.; Curi, N. 2008. Efeito da calagem na nutriçáo mineral e no crescimento inicial do eucalipto a campo em Latossolo húmico da Zona da Mata. Scientia Forestalis, 36(80): 255-263.

Santana, R.C.; Barros, N.F.; Neves, J.C.L. 1999. Produção de biomassa e conteúdo de nutrientes de procedências de Eucalyptus grandis e Eucalyptus saligna em alguns sítios florestais do Estado de São Paulo. Scientia Forestalis, 56: 155-169.

Santana, R.C.; Barros, N.F.; Neves, J.C.L. 2002. Eficiência de utilização de nutrientes e sustentabilidade da produção em procedências de Eucalyptus grandis e Eucalyptus saligna em sítios florestais do estado de São Paulo. Revista Árvore, 26(4): 447-457.

Santos, L.A. 2010. Estudo do controle da matocompetição em reflorestamento com eucalipto em Paragominas, estado do Pará. Dissertação de Mestrado, Universidade Federal Rural da Amazônia, Belém, Pará. 99pp.

Sgarbi, F. 2002. Produtividade do Eucalyptus sp. em função do estado nutricional e da fertilidade do solo em diferentes regióes do Estado de São Paulo. 2002. Dissertação Mestrado, Escola Superior de Agricultura Luiz de Queiroz, Piracicaba, São Paulo. 114pp.
Silva, K.R., Minetti, L.J.; Fiedler, N.C. Venturoli, F.; Machado, E. G. B.; Souza, A. P. 2004. Custos e rendimentos operacionais de um plantio de eucalipto em região de cerrado. Revista Árvore, 28(3): 361-366.

Silva, S.R.; Barros, N.F.; Novais, R.F. \& Pereira, P.R.G, 2002. Eficiência nutricional de potássio e crescimento de eucalipto influenciados pela compactação do solo. Revista Brasileira de Ciência do Solo, 26:1001-1010.

Sousa, S.M. 2006. Comportamento sazonal de sete genótipos de coqueiro (Cocos nucifera L.) nas condiçóes ecológicas de Moju no Estado do Pará. Dissertação de Mestrado, Universidade Federal Rural da Amazônia, Belém, Pará. 65pp.

Souza, C.R.; Rossi, L.M.B.; Azevedo, C.P.; Lima, R.M.B. 2004. Comportamento da Acacia mangium e de clones de Eucalyptus grandis x E. urophylla em plantios experimentais na Amazônia Central. Scientia Forestalis, 65: 95-101.

STATSOFT, INC. 2009. Statistica for Windows-Computer program manual. Tulsa.

Tonini, H.; Arco-Verde, M.F.; Schwengber, D.; Mourão Junior, M.M. 2006. Avaliação de espécies florestais em área de mata no estado de Roraima. Cerne, 12(1): 8-18.

Vilas Bôas; O.; Max, J. C. M.; Melo, A. C. G. 2009. Crescimento comparativo de espécies de Eucalyptus e Corymbia no município de Marília, SP. Revista do Instituto Florestal, 21(1): 63-72.

Wadt, P.G.S. 2004. Nutritional status of Eucalyptus grandis clones evaluated by critical level and DRIS methods. Revista Árvore, 28(1): 15-20, 2004.

Wadt. P.G.S.; Novais, R.F.; Alvarez, V.H.; Barros, N.F.; Dias, L.E. 1999. Variaçóes no estado nutricional de eucaliptos em função do material genético e da idade da árvore. Pesquisa Agropecuária Brasileira, 34(10): 1797-1803.

Recebido em: 30/05/2011

aceito em: 17/01/2012 